\title{
Percutaneous Cystolithotripsy As A Reliable Modality To Treat Pediatric Vesiculolithiasis
}

\author{
Gupta DK ${ }^{1}$, Mishra SMํำ
}

\begin{abstract}
Background: Primary vesical stones are common in children in underdeveloped and developing countries. The treatment options available for managing bladder calculi include transurethral cystolithotripsy, open cystolithotomy and shock wave lithotripsy (SWL). Although the majority of vesical calculi in adults can be treated by transurethral lithotripsy, this procedure is restricted in children due to the narrow caliber of the urethra. For this reason, percutaneous cystolithotripsy (PCCL) is a good choice as a safe and effective method for the treatment of bladder stones in children. Aim of the Study: The study was aimed to evaluate outcome of PCCL in pediatric population coming with vesiculolithiasis in our center. Materials and Methods: Pediatric age group patients diagnosed as vesical calculus were undertaken for PCCL. Ten patients who presented between November 2014 to December 2015 , were included. The procedure was done under general anesthesia. After performing cystoscopy, suprapubic puncture was made and tract dilated upto $26 \mathrm{Fr}$. Nephroscope was used for visualization and pneumatic lithotripsy for fragmentation of the stone followed by removal of all fragments. Perurethral and suprapubic catheters were placed at the end to be removed on $1^{\text {st }}$ and $2^{\text {nd }}$ post operative day, respectively. Results: Median age of the patients was 5.5 (3-13) years. Majority were male patients from hilly region of western Nepal. Mean stone size was $15 \mathrm{~mm}$. All patients were rendered stone free with average operative time of 32.2 minutes. Except one minor complication of mucosal injury patients were discharged after mean hospital stay of 3.9 days. Conclusion: Percutaneous suprapubic lithotripsy is a safe and effective method for the treatment of bladder stones in children. It is fast and associated with negligible complications.
\end{abstract}

Key words: Bladder calculi, children, cystolithotripsy

\section{INTRODUCTION}

Bladder calculi have plagued mankind since time eternal. Archeologists discovered a stone resting in the pelvis of an ancient Egyptian skeleton dating back more than 7000 years ${ }^{1}$. Fortunately, in the past 50 years, the incidence of vesical calculi in developed countries has declined significantly. Currently, they represent roughly $5 \%$ of all urinary calculi in the Western world ${ }^{2}$. Underdeveloped nations still suffer from endemic bladder calculi, especially in children ${ }^{3}$.

Various modalities, as conventional surgery, shock wave lithotripsy (SWL), suprapubic and transurethral cystolithotripsy are used to treat the vesical calculi. With all the options of treatment, the method of choice should be both relatively noninvasive and expeditious. Open cystolithotomy is only occasionally needed ${ }^{4}$. The majority of vesical calculi in adults can now be treated perurethrally with the use of lithotripsy. However, the use of these devices is restricted in pediatric patients because of the narrow caliber of the urethra, ${ }^{5,6}$. The

1. Dr. Dipesh Kumar Gupta

2. Prof. S. M. Mishra

Address for correspondence:

Dr. Dipesh Kumar Gupta

Department of Surgery

Nepalgunj Medical College \& Teaching Hospital,

Nepalgunj, Banke, Nepal

Email: drdipeshgupta@yahoo.com role of SWL is restricted due to high retreatment rate and difficulty in the voiding of fragments. A percutaneous suprapubic approach to the bladder circumvents the problem of the narrow urethra in these situations ${ }^{7}$.

Using the well established principles of percutaneous access and tract dilation that have been developed with renal stone surgery, one can treat bladder stones through a percutaneous suprapubic approach in an expeditious manner. We review our experience in treating pediatric vesiculolithiasis by suprapubic approach.

\section{MATERIALS AND METHODS}

This observational study was conducted at Nepalgunj Medical College, Nepalgunj Hospital, Nepalgunj in urology unit of Department of Surgery from November 2014 to December, 2015. A total of 10 pediatric patients underwent percutaneous cystolithotripsy (PCCL) during this period.

The diagnosis was based on ultrasonography and plain X-rays. Stone diameter was determined by reviewing plain $\mathrm{X}$-rays. Urine was tested for culture and sensitivity.

The procedure was performed under general anesthesia. It was initiated with urethrocystoscopy to exclude any subvesical obstruction (urethral valve, urethral stricture) or rather to push the urethral stone back into the bladder (one patient in current series). Bladder was distended with saline and suprapubic puncture was made and confirmed with the same telescope. Floppy tip guide wire was inserted and approximately $1 \mathrm{~cm}$ 
incision made over puncture site. Fascial dilator up to $12 \mathrm{Fr}$ was used and placing guide rod one step dilatation was done with amplatz dilator of $26 \mathrm{Fr}$ (Figure 1).

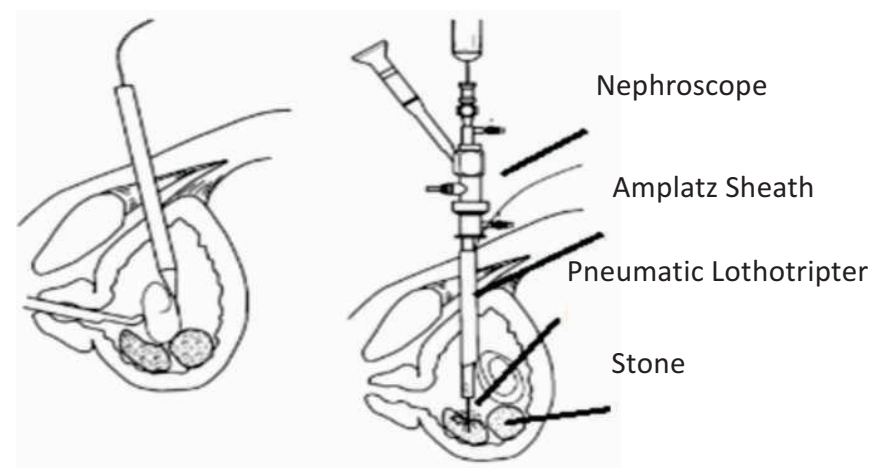

Figure 1: Diagrammatic representation of PCCL

The procedure was performed under direct vision by telescope. Nephroscope was introduced and after full inspection stone was taken intact or after fragmentation depending on the size. After the procedure suprapubic catheter was placed and left for one day while perurethral catheter was removed on $2^{\text {nd }}$ post operative day.

\section{RESULTS}

A total of 10 patients of pediatric age group presented to us during one year of study period. Majority (9/10) were from hilly region of western Nepal. None of the patients had previous history of vesical calculus.

Median age of the patients was 5.5 years. Male outnumbered the procedure with ratio of $8: 2$. With median symptoms duration of 6.5 days, majority presented with dysuria and acute urinary retention (Table I). Median size of the stone was $17 \mathrm{~mm}$. All patients were rendered stone free in one single session (Table II). All patients were voiding spontaneously at the time of discharge. There was no postoperative complication noted in short term follow up.

\section{DISCUSSION}

Nowadays, urolithiasis in childhood is rare in the developed world, it represents $1-5 \%$ of all urinary tract stones ${ }^{2}$. Moreover, urinary bladder stone is very rare $^{8}$. However, in the developing countries, the occurrence of pediatric urolithiasis is $30 \%$ of all urinary tract stones, and the so-called endemic bladder stone is still common in the childhood in the Third World ${ }^{9}$.

As opposed to the elderly, where the stones are invariably secondary to outflow obstruction or infection ${ }^{10}$, childhood vesical calculi are primary in nature, caused most often by dietary deficiency ${ }^{11}$. In adults, transurethral disintegration for

\begin{tabular}{|c|c|}
\hline Variables & Values \\
\hline Age in years(Mean \pm SD) & $5.4 \pm 3.02$ \\
\hline Gender (Male:Female) & $8: 2$ \\
\hline Symptom Duration in days (Mean \pm SD) & $16 \pm 26.6$ \\
\hline Clinical Presentation & 7 \\
\hline Dysuria & 4 \\
\hline Acute retention of urine & 4 \\
\hline Increased frequency & 6 \\
\hline Decreased stream of urine & $15 \pm 5$ \\
\hline Stone size in millimeter (Mean \pm SD) & \\
\hline
\end{tabular}

Table I: Patient characteristics $(n=10)$

\begin{tabular}{|c|c|}
\hline Variables & Values \\
\hline Operative time in minutes (Mean \pm SD) & $32.2 \pm 6.3(25-45)$ \\
\hline Stone free rate & $100 \%$ \\
\hline Hospital stay in days (Mean \pm SD) & $3.9 \pm 2.23$ \\
\hline Retreatment rate & 0 \\
\hline Intraoperative complications (mucosal injury) & 1 \\
\hline Postoperative complications & 0 \\
\hline Additional procedures & 0 \\
\hline
\end{tabular}

Table II: Operative and post operative data 
urinary bladder stones is a common method and with the availability of different energy sources, virtually all vesical calculi can be treated endoscopically. However, urethral injury is a strong possibility in few instances specially in larger stones $^{5,12}$. Similarly, in children, narrow caliber of the urethra precludes the use of this procedure ${ }^{13}$.

High male to female ratio not exactly known but is similar to other studies ${ }^{5,7}$. Clinical presentations are similar to other studies where vesiculolithissis was studied ${ }^{14}$. With percutaneous suprapubic approach, $26 \mathrm{Fr}$ or if needed $30 \mathrm{Fr}$ to $32 \mathrm{Fr}$ Amplatz sheath can be introduced into the bladder without urethral injury. In this manner, the large and hard stones can be disintegrated and removed in big fragments, so the intervention can be fast ${ }^{7}$. Here, in our series also only one minor complication of mucosal injury was noted which did not have any unfavorable outcome. Also, the procedure was fast owing to larger sheath size and fast fragmentation.

In current series, none of the additional procedure was required because mostly it is primary vesical calculus in this age group. In adults, or in cases where features of obstruction are present, they might require other concomitant procedures to relieve obstruction ${ }^{14}$.

The morbidity of PCCL is significantly less than that of open cystolithotomy. Hospital stay is far shorter and chances of wound infection is negligible ${ }^{5}$. Our result is consistent with the successful and encouraging results of other authors ${ }^{12,15}$.

\section{CONCLUSION}

Percutaneous suprapubic lithotripsy is a safe and effective method for the treatment of bladder stones in children. It is fast and associated with negligible complications.

\section{REFERENCES}

1. Shattock SG. A prehistoric or predynastic Egyptian calculus. Translations of Pathologic Society of London. 1905;56:275.

2. Hulbert JC, Reddy PK, Gonzalez R, Young AD, Cardella J, Amplatz K, et al. Percutaneous nephrostolithotomy: an alternative approach to the management of pediatric calculus disease. Pediatrics. 1985 Oct;76(4):610-2.

3. Sepahi MA, Heidari A, Shajari A. Clinical manifestations and etiology of renal stones in children less than 14 years age. Saudi J Kidney Dis Transpl. 2010 Jan;21(1):181-4.

4. Rasheed SA ZB, Nisar SA, Saiyal AR. Intracorporeal cystolithotripsy in children. JCPSP. 2001;11:156-57.

5. Agrawal MS, Aron M, Goyal J, Elhence IP, Asopa HS. Percutaneous suprapubic cystolithotripsy for vesical calculi in children. J Endourol. 1999 Apr;13(3):173-5.

6. Salah MA, Holman E, Toth C. Percutaneous suprapubic cystolithotripsy for pediatric bladder stones in a developing country. Eur Urol. 2001 Apr;39(4):466-70.

7. Salah MA, Holman E, Khan AM, Toth C. Percutaneous cystolithotomy for pediatric endemic bladder stone: experience with 155 cases from 2 developing countries. J Pediatr Surg. 2005

\section{Oct;40(10):1628-31.}

8. Carvajal Busslinger MI, Gygi C, Ackermann D, Kaiser G, Bianchetti M. Urolithiasis in childhood: when to do what? Eur J Pediatr Surg. 1994 Aug;4(4):199-200.

9. Johnson O. Vesical calculus in Ethiopian children. Ethiop Med J. 1995 Jan;33(1):31-5.

10. Kancha RK, Anasuya A. Contribution of vitamin A deficiency to calculogenic risk factors of urine: studies in children. Biochem Med Metab Biol. 1992 Feb;47(1):1-9.

11. Douenias R, Rich M, Badlani G, Mazor D, Smith A. Predisposing factors in bladder calculi. Review of 100 cases. Urology. 1991 Mar;37(3):240-3.

12. Ikari O, Netto NR, Jr., D'Ancona CA, Palma PC. Percutaneous treatment of bladder stones. J Urol. 1993 Jun;149(6):1499-500.

13. Wollin TA, Singal RK, Whelan T, Dicecco R, Razvi HA, Denstedt JD. Percutaneous suprapubic cystolithotripsy for treatment of large bladder calculi. J Endourol. 1999 Dec;13(10):739-44.

14. Sigdel G S AA, Lamichhane N, Belokar W K. Transurethral use of nephroscope in the management of bladder stone. J Col of Med Scien. 2013;9(1):14-8.

15. Badlani GH, Douenias R, Smith AD. Percutaneous bladder procedures. Urol Clin North Am. 1990 Feb;17(1):67-73. 